DOI: $10.14526 / 2070-4798-2020-15-1-59-66$

\title{
Psychological characteristics of students' personality different specialties
}

\author{
Natalya Yu. Tarabrina ${ }^{1 *}$, Elena Yu. Grabovskaya ${ }^{2}$,Yuriy V. Kraev ${ }^{1}$ \\ ${ }^{1}$ Moscow Aviation Institute (National Research University), \\ Moscow, Russia \\ ORCID: oooo-ooo3-1469-5010,nata-tarabrina@mail.ru* \\ ORCID: oooo-OoO2-2034-3938yury.kraev@mail.ru \\ ${ }^{2}$ Taurian Academy of Vernadsky Crimean Federal University \\ Simferopol, Russia \\ ORCID: oooo-ooo3-1912-7063grabovskaya13@mail.ru
}

\begin{abstract}
Compliance with individual typological characteristics of the student to the chosen direction contributes to successful adaptation to higher education and readiness for future professional activities. The goal is to identify the psychological characteristics of students-doctors, engineers, and lawyers. Materials. Future doctors $(\mathrm{n}=80)$, lawyers $(\mathrm{n}=50)$, and engineers $(n=50)$ studied psychological characteristics of the individual in 180 students of 1-3 courses (1725 years). The program «Mini-mult» of the medical diagnostic hardware and software complex «Biomysh-research» («Nerolab», Russia) was used. Results. Students of different specialties have intergroup and individual differences in neurodynamic and cognitive functions. The most significant difference was found on the scales 1, 2, 6, 7 (P 0,05-0,01). The character of the students-future doctors and lawyers personality pattern, has a «peak-like», three-phase pattern and there are no significant differences between contrasting «peaks». The average psychological profile of the students personality and future engineers is «linear»- all its indicators are in the range between $45 \mathrm{~T}$ and $55 \mathrm{~T}$. Such a profile is found in people who belong to the concordant norm. Conclusion. According to the indicators of the three evaluation scales (L, F, K), students of all the study groups are characterized by high openness and a desire to present themselves in a more favorable light. Psychological profiles of students, doctors and lawyers are similar in nature. Engineering students are confident, happy with themselves and their surroundings, sociable, optimistic and cheerful. However, their level of anxiety is higher than that of a group of law students. It is recommended to create a system of organizational and pedagogical conditions for the formation and development of «sinking components of professional mobility» for students of various specialties.
\end{abstract}

Keywords: psychological characteristics of the individual, students, doctors, lawyers, engineers.

For citation: Natalya Yu. Tarabrina*, Elena Yu. Grabovskaya, Yuriy V. Kraev. Psychological characteristics of students' personality different specialties. Russian Journal of Physical Education and Sport. 2020; 15(1): 50-56. DOI: 10.14526/2070-4798-2020-15-1-59-66

\section{INTRODUCTION}

One of the leading tendencies of modern educational situation development, which is realized on the basis of global changes in social-economic sphere of our society, is attention to new level staff potential formation $[1,2]$.

For a successful crises escape and the tempo of economics development government takes the measures, which include the objectives, directed towards the level of all productive relations intensification [3]. It is possible in terms of the working staff professional training quality and in terms of the highly-productive working places increase (HPWP) number [4].

During vacancies for HPWP announcement many organizations and industrial productions have the demands for the potential workers' professionally important psychophysiological qualities (PIPQ) [5]. At the same time special attention is paid to physical, functional and psychological parameters of the future workers [6]. It is supposed that professional working capacity of a person, which is based on special knowledge, skills and abilities and a range of professionally significant physical and psychic qualities, influences labor productivity [7]. We revealed feedback, when the profession influences a person, forming different "psychophysiological portraits" [6,7]. For example, medical, juridical or economic influence on a person is multidimensional, for some subjects 
harmoniously controlled, empathic, for othersimpulsive, emotionally unsteady, frustratoire. Depending on the peculiarities of professional activity there is varied frequency of different influence kinds [4].

It becomes obvious that the problems of professional selection in terms of severe modern demands gain not only great urgency, but also can have great value both for employer and for the specialist. The problem of specialists with the definite HPWP selection appears not only before the establishments and organizations, which offer HPWP, but before higher educational establishments, which realize the future specialists training [5].

M.S. Emmert and other authors [8] and our own earlier research works [4] show that professionally important qualities of doctors, lawyers and engineers include general endurance (as for many professions, as it determines the level of specialist's working capacity and his fatigability) [10], static and dynamic power of "pose" muscles (of spine, abdomen, shoulder girdle) [10], dexterity of muscle apparatus of hands [11]; communicative and organizational abilities, attention switch, logical thinking, operative memory and the ability of selfcontrol (stress resistance) [12] (picture 1). However, for complete characteristic of psychophysiological status of students of different specialties it is necessary to study psychological characteristics of a personality.

The aim of the research is to reveal psychological characteristics of students- doctors, engineers and lawyers personality.

\section{MATERIALS AND METHODS}

Psychological characteristics of the personality were studied among 180 students of the 1st -3rd courses (17-25 year-old), the future lawyers $(n=50)$ and engineers $(n=50)$. The program «Minimult» of the medical diagnostic hardware and software complex «Biomouse-research» (Biomyshissledovatelskaya) («Nerolab», Russia) was used. «Mini-mult» questionnaire was created by Swedish psychologist James C. Kincannon (1968) [13] and was adapted in Russian variant by V.P.Zaytsev (1981) [14]. It is a short variant of Minnesotan multiaspect personality test MMPI - methodology of personality many-sided study, for express-estimation of psychic adaptation of big amount of respondents in terms of dynamic self-control. This test is used not only in the clinic for the personality structure and psychic states estimation, but also is used for healthy people study (students, athletes and other people) in order to get additional information about the characteristics of a personality and possible deviations (for example, psychopathic traits of character revelation) [15].

The test among students was held in auditoriums before the lessons. At a preliminary stage all respondents were registered in a computer database. Then each student fulfilled the test, which included 71 questions (statements). After the program start there appeared the dialogue box on the screen. The dialogue box had the question and it was offered to choose the answer. Questions were in sequence. Each respondent was tested no more than 15 minutes. Results interpretation was held according to 11 scales. Three evaluation scales (L, $\mathrm{F}, \mathrm{K}$ ) reflect the respondent's sincerity, the degree of results validity and the volume of correction. It is introduced by excessive caution. The rest 8 scales estimate the features of a personality. Results handling was held using the set of special tables. They transform the received points into T-points. The indices higher than 70T and lower than 40T were considered as a deviance [14]. The results of the studies were statistically handled, using «STATISTICA 10.0». Parametric methods were used, the validity of the received results differences was determined with the help of Student t-test in terms $\mathrm{p}<0,05$. As the measure of the central tendency arithmetical mean (M) was used, as the measure of dispersion standard error of the arithmetical mean (m) was used.

\section{RESULTS AND DISCUSSION}

During the held research we received the results. They characterize psychological characteristics of students' personality -doctors, lawyers and engineers. It is known that T-points value of the main profile scales, which are within the range of 40T-70T, are considered a norm and are called "corridor of norm". Among the sampling of students-doctors all scales of the main profile are 
within the range of $47,60 \pm 1,20 \mathrm{~T}$ till $77,13 \pm 2,00 \mathrm{~T}$, with peaks. They correspond with the scales F, 3, 6, 8 (table 1). Such kind of profile can be considered "peak-like" or "three-phase". The leading typical traits of this profile are the traits. They are typical for the scales, corresponding with the "peaks". The greatest T-points value of the main profile scales corresponds with F scale - - 77,13 $\pm 2,00 \mathrm{~T}$ (picture 1).Such a high value of $F$ scale profile can prove uncertain answers. Sometimes it proves the need for self-expression among young people with not high thinking sensitivity, the inkling for conflict behavior [18]. The value of the rest T-points of the main profile scales are within the range of the upper limit of norm. The contrasting "peaks" are seen according to the scales of hysteria (Hy), paranoia state $(\mathrm{Pa})$, schizophrenia state (Se).

As the values of $\mathrm{T}$-points according to these scales are within the limits of the norm, we can say that a student-doctor is characterized by some difficulty in social adaptation, the desire to attract attention, be special, not having clear grounds for it, an artistic demonstration of own "Self". For such students it is typical to have nonstandard approaches and ideas. They are sometimes far from their realization, not always practical.

The received results of the lawyers' study are presented in table 1 and are graphically interpreted in picture 1. The averaged psychological profile of students-lawyers analysis showed the same "threephase" personality picture, as in case of studentsdoctors. In one case "peaks" correspond with the scales of students- doctors and don't have valid differences. The values of almost all basic scales are within the norm, but are closer to "the average corridor".

Table 1 -T-points value of the students- doctors $(n=80)$, students-lawyers $(n=50)$, students-engineers $(\mathrm{n}=50)$ main scales

\begin{tabular}{|c|c|c|c|c|}
\hline \multirow{2}{*}{ № } & \multirow{2}{*}{ SCALES } & \multicolumn{3}{|c|}{ Indices } \\
\cline { 3 - 5 } & & Doctors & Lawyers & Engineers \\
\hline L & Lie & $50,62 \pm 1,40$ & $52,25 \pm 1,30$ & $48,92 \pm 1,50$ \\
\hline F & Validity & $77,13 \pm 2,00$ & $72,33 \pm 3,90$ & $51,31 \pm 1,50$ \\
\hline K & Correction & $48,56 \pm 7,60$ & $52,38 \pm 7,00$ & $48,02 \pm 1,30$ \\
\hline $1(\mathrm{Hs})$ & Hypochondria & $55,03 \pm 1,70$ & $46,00 \pm 3,30$ & $54,00 \pm 1,60$ \\
\hline $2(\mathrm{D})$ & Depression & $61,00 \pm 2,00$ & $58,00 \pm 2,70$ & $51,68 \pm 2,10$ \\
\hline $3(\mathrm{Hy})$ & Hysteria & $64,05 \pm 2,00$ & $61,35 \pm 1,60$ & $56,78 \pm 2,00$ \\
\hline $4(\mathrm{Pd})$ & Psychopathy & $52,35 \pm 2,00$ & $46,17 \pm 2,00$ & $44,26 \pm 1,90$ \\
\hline $6(\mathrm{~Pa})$ & Paranoia state & $68,98 \pm 1,10$ & $61,79 \pm 1,40$ & $51,65 \pm 2,00$ \\
\hline $7(\mathrm{Pt})$ & Psychasthenia & $47,60 \pm 1,20$ & $36,66 \pm 1,80$ & $55,92 \pm 2,00$ \\
\hline $8(\mathrm{Se})$ & Schizophrenia state & $63,36 \pm 2,10$ & $53,23 \pm 2,20$ & $52,71 \pm 1,60$ \\
\hline $9(\mathrm{Ma})$ & Hypomania & $61,52 \pm 1,20$ & $60,14 \pm 1,60$ & $50,18 \pm 1,7 \mathrm{O}$ \\
\hline
\end{tabular}

The exception is the scale of psychasthenia (Pt). T-points value of this scale are extremely low $36,66 \pm 1,80 \mathrm{~T}$. The value of psychasthenia scale is $23 \%$ lower than among students- doctors. It proves the absence of caution in deeds and scrupulosity in the questions of morality, egocentrism, decreased ability to empathy, non-conformity of mindsets, severe manner of behavior, cynicism. Such decrease according to the $7^{\text {th }}$ scale proves uncritical attitude to own "Self", to own abilities revaluation. It can be the reason for adaptation violation.

In students-lawyers, the same as in students-doctors the greatest value of T-points of the main profile scales corresponds with $\mathrm{F}$ scale$72,33 \pm 3,90 \mathrm{~T}$. Absolute values of this scale are $7 \%$ lower, than in students-doctors. Such moderate $\mathrm{F}$ scale indices increase can be connected with the inner tension and dissatisfaction in first-year students with the adaptation to changed situation in communication and the specificity of education [19]. 


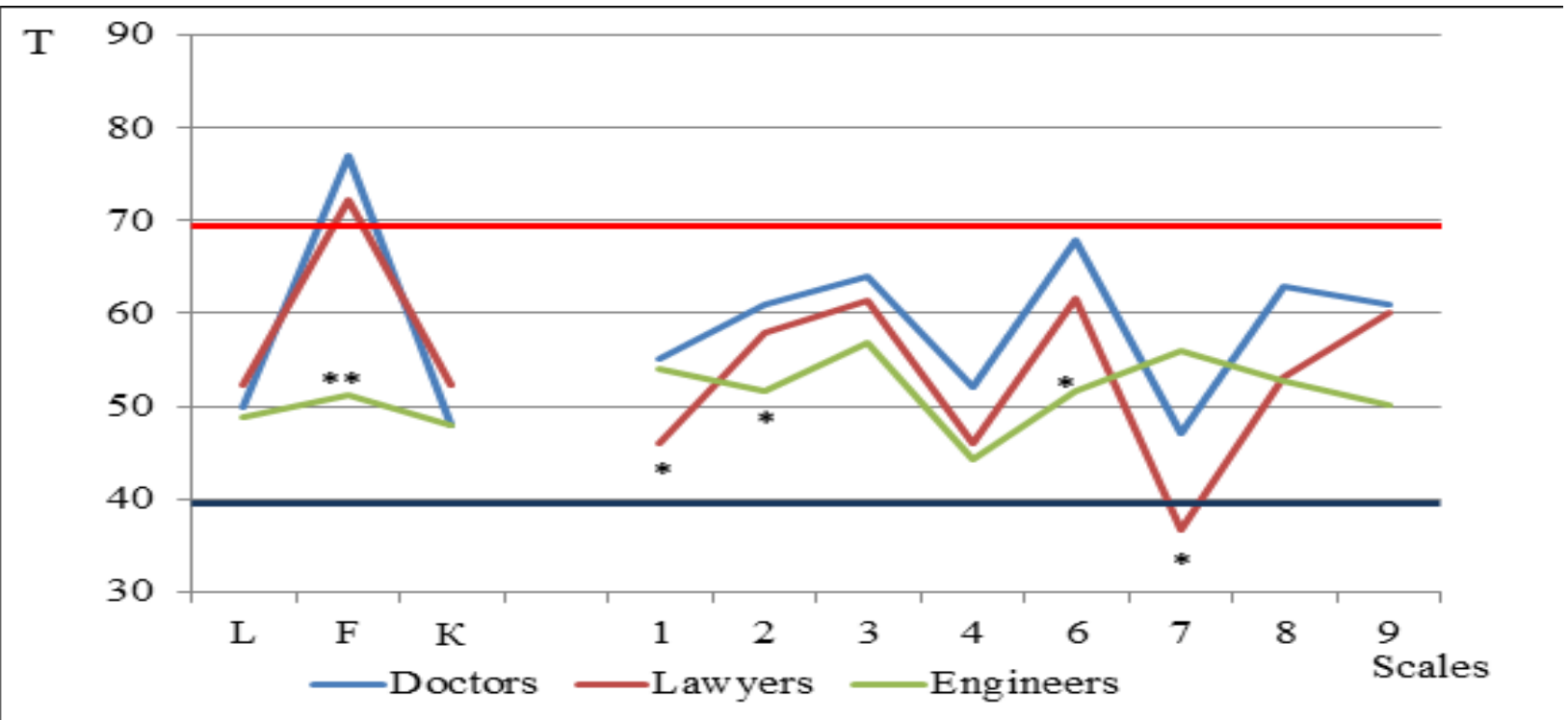

Notes. L - lie scale, F - validity scale, $\mathrm{K}$ - correction scale, 1 - hypochondria scale, 2 - depression scale, 3 - hysteria scale, 4 psychopathy scale, 6 - paranoia state scale, 7 - psychasthenia sclae, 8 - schizophrenia state scale, 9 - hypomania scale. ${ }^{*}-p<0,05$ - significance level; ${ }^{* *}-\mathrm{p}<0,01$ - significance level Student t-test

Fig. 1. Averages psychological profile of students -doctors $(n=80)$, students-lawyers $(n=50)$, studentsengineers $(n=50)$

Psychological profile of students-engineers depression scale (D) students- engineers have the differs considerably from the profile of studentsdoctors and students-lawyers. According to the scales of validity there was the difference in $\mathrm{F}$ scale - among students- engineers it was 48,69\% lower $(\mathrm{p}<\mathrm{0}, 01)$, than among other respondents. The scales of lie and correction were within the limits of norm and didn't differ considerably. In general the averaged profile of students-engineers can be included into "linear" one, as its all indices are within the limits between $45 \mathrm{~T}$ and $55 \mathrm{~T}$. Picture 1 shows that students-engineers had the inversion according to the indices of $\mathrm{D}$ and Pt scales. The level of anxiety (according to the scale of psychasthenia) among them was $55,92 \pm 2,00 \mathrm{~T}$, which is $52,53 \%(\mathrm{p}<0,05)$ higher than the level of the students-lawyers group and corresponds with the norm.

Comparative analysis of results, received in all three defined groups, showed considerable difference according to scales 1, 2, 6, 7. According to the basic scale of hypochondria (Hs) studentslawyers have the lowest value of T-points, which is $46,00 \pm 3,30 \mathrm{~T}$. In the future lawyers the value of this scale is $16 \%(\mathrm{p}<0,05)$, lower, than in studentsengineers. It can be explained by the specificity of medical education in doctors and by the inclination for own accuracy, steadiness and working capacity demonstration in engineers. According to the basic

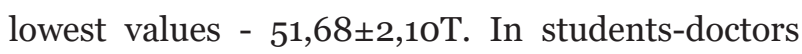
and students-lawyers the volume of T-points according to this scale is $12,2 \%$ and $18,0 \%$ higher. Such tendency can prove great resistance of the future lawyers to depressive-anxious states. In students-engineers such results prove a low level of anxiety, activity, communicativeness, the sense of own importance, power, energy and cheerfulness. At the same time the indices of all three groups are within the limits of "norm corridor". According to the basic paranoia state $(\mathrm{Pa})$ scale the lowest values, which correspond with the norm, were in studentsengineers. In students- doctors and studentslawyers T-points values according to paranoia state (Pa) scale were 33,6\% ( $\mathrm{p}<0,05)$ and 19,6\% higher and were close to the upper limit of the norm. According to the basic scale of psychasthenia (Pt) students-engineers also didn't have any deviations from the norm. Students-doctors and studentslawyers have negative "peaks" of T-points value according to psychasthenia (Pt) scale. In doctors the results are $14,9 \%$ lower. In lawyers the results is $34,4 \%$ lower and is beyond the lower limit of "norm corridor". Higher values according to scale 8 were in students-doctors, than in the future lawyers and engineers, $15,5 \%$ and $24 \%$ higher (table 1 , picture 1 ). In general the values according to all basic scales in 
students-engineers and students-lawyers are lower and are closer to the norm in comparison to the same results in students-doctors.

\section{Discussion}

The research works, devoted to psychological characteristics of students' personality study in students of different specialties, are still very urgent. In the opinion of some authors [9], students' age is the final stage of socialization. The main aim of this age is profession and the type of educational establishment choice. It leads to differentiation of students' way of life at different educational establishments, interests and responsibility range broadening. Psychological characteristics influence the character of the individual, his success and failures in the definite professional activity, the interaction with other people in professional and personal spheres [19]. Many authors study differences in psychological characteristics of students' personality of technical, artistic specialties, programmers $[8,19,20]$. At the same time, most native authors consider, that the main factor in personal characteristics development is a person's way of life and his professional activity. "It determines personal characteristics of the subjects, their professional motivation” [20]. Our research work studied psychological characteristics of a personality in students-doctors and the future lawyers and engineers. According to the results of testing using multiaspect MMPI questionnaire we studied the personality features of different specialties students. In accordance with T-points of L and K scales students of all three groups have sufficiently high sincerity and the tendency to present oneself in a favorable light, demonstrating social norms observance. According to $\mathrm{F}$ scale students-doctors and students-lawyers have high results. They prove low validity of answers and high level of anxiety concerning the test. Psychological profiles of students-doctors and students-lawyers have much in common. Students-doctors and students-lawyers can show themselves better in the situations. In these situations it is necessary to change own role, where there are short-term contacts, the ability to adapt to different people. Decisiveness, flexibility of behavior with low level of anxiety, confidence during decisions making are the characteristics typical for the future doctors and lawyers. These characteristics would help to realize professional activity in the future [14]. Probably straightforwardness, sense of competition, desire to estimate own achievements high, some neglect of behavior rules are typical for them.

Psychological profile of studentsengineers is different. For them low level of anxiety, activity, communicativeness, sense of own significance, power, energy is typical. One of the psychological characteristics of engineers is the tendency to preserve constant interests, mindsets, determination, flexibility of behavior with low level of anxiety, confidence during decisions making. Such psychological picture corresponds with the profile of technical specialties students. In professional activity of engineers such qualities are extremely important. The received results correspond with the results of our previous research works and with the opinion of several authors $[4,21,22,23]$. A. Baurina thinks that for the future engineers it is typical to have the following characteristics: low anxiety level, emotional comfort, self-acceptance, adaptability, low level of emotionality, rational behavior during stress. [21]. Thus, the held research works prove the presence of peculiarities in psychological profile of students-doctors, students-lawyers and studentsengineers. The success and failure in the definite professional activity, the style of interpersonal communication, interaction with other people in professional and personal spheres depend on these characteristics [19].

\section{CONCLUSION}

According to the indicators of three evaluation scales (L, F, K), students from all studies groups have high level of sincerity and a desire to present themselves in a favorable light.

Psychological profiles of students-doctors and lawyers are similar. The stating "peaks" are defined according to the scales of hysteria, paranoia state schizophrenia state. It shows constant dissatisfaction and steady desire to achieve the aim. Decisiveness, flexibility of behavior with low level of anxiety, confidence during decisions making are the characteristics typical for the future doctors and lawyers. Students-engineers are confident, are 
satisfied with themselves and their surroundings, sociable, optimistic and cheerful. However, their level of anxiety is higher than that one in a group of students-lawyers. It is recommended to create a system of organizational and pedagogical conditions for the "stay-put components of professional mobility" formation and development in students of different specialties.

\section{REFERENCES}

1. Tarabrina Natalia Yu, Tikhonov Alexey I \& Kraev Yuriy V. Professional-applied physical training of future HR specialists. Revista Espacios. 2020; 41:22.

2. Zheltenkov A.V., Fedotova M.A., Tikhonov A.I. Analysis of the quality of professional training of personnel management specialists in higher educational institutions. Bulletin of the Moscow state regional University. 2018; 2: 61-70. DOI: 10.18384/2310-6646-2018-2-6170.

3. Mikhailov A.A., Fedotova M.A., Tikhonov A.I., Novikov S.V. Problems of professional self-determination of students. Financialeconomics. 2018; 6: 206-210.

4. Tarabrina N.Yu. Psychophysiological estimation of health among students-lawyers. Teoriya I praktika fizicheskoj kul'tury = Theory and practice of physical culture. 2015; 1: 52-54 [In Russ., In Engl.].

5. Kraev Yu.V., Tarabrina N.Yu. Comparative analysis of the features of the stress manifestation in physical education teachers and students, Moscow economic journal. 2019; 1: 63.

6. Fedotova M.A., Tikhonov A.I., Novikov S.V. Estimating the effectiveness of personnel management at aviation enterprises. Russian Engineering Research, 2018; 38(6): 466-468. DOI:10.3103/S1068798X1

7. Prosvirina N.V., Tikhonov A.I., Novikov S.V. Education of students in the context of cultural development. Moscow economic journal. 2018; 3: 19.

8. Emmert M.S. Assessment of efficiency of development of professionally significant qualities of future specialists in personnel management. Omsk scientific Bulletin. 2014; 5(132): 177-178.

9. Melnichenko E. V., Tarabrina N.Yu., Parkhomenko A.I. Miovisceral reflex correction of vestibular reactions of cardiovascular system in athletes. Tavricheskij medko-biologicheskij vestnik.
2010; 13(3): 133 [In Russ.].

10. Tarabrina N.Yu. Miorelaxation in the system of scoliotic changes correction in athletes' neck-thoracic spine. Teoriya I praktika fizicheskoj kul'tury $=$ Theory and practice of physical culture . 2016; 4: 30-32 [In Russ., In Engl.].

11. Melnicheko E. V., Tarabrina N.Yu., Mishin N. P., Ozerova L. A. Motor qualities correction in terms of vestibular loads by means of active traction-rotary miorelaxation method. Uchenye zapiski Tavricheskogo Nacional'nogo Universiteta imeni Vernadskogo. Seriya: biologiya, himiya. 2008; 21(3): 88-92 [In Russ.].

12. Kraev Yu.V., Semina A.P. An overview of the types of aggression in human resources. Moscow economic journal. 2017; 4: 70.

13. Kincannon JC. Prediction of the standard MMPI scale scores from 71 items: the mini-mult. J Consult Clin Psychol. 1968 Jun; 32(3): 319-325. DOI: 10.1037/hoo25891.

14. Zaitsev V. P. Version of the psychological test MIPI-M. Psychological journal. 1981; 3: 118-123.

15. Woodward, Christel \& Goodman, John \& McLean, Anthony. Comparisons of the MMPI and Mini-Mult. Canadian Journal of Behavioural Science/Revue canadienne des sciences du comportement. 1973; 5: 76-82. DOI: 10.1037/ hoo82331.

16. Jr, E. Personality Traits of Athletes as Measured by the MMPI. Research Quarterly. American Association for Health, Physical Education and Recreation, 2013; 29: 127-138. DOI: 10.1080/10671188.1958.10612974.

17. Rattanapitoon, Schawanya \& Rattanapitoon, Natthakapach \& Ueng-arporn, Naporn. Medical Students Personality using Minnesota Multiphasic Personality Inventory (MMPI) Psychological Test. Conference: International Conference on Molecular Biology and Biomedicine. 2013.

18. Boscan, Deisy \& Penn, Nolan \& Velasquez, Jon \& Reimann, Joachim \& Gomez, Nelson \& Guzman, Miguel \& Berry, Elvia \& Infantes, Lourdes \&Jaramillo, Luis\& Romero, Maritza. MMPI2 profiles of Colombian, Mexican, and Venezuelan university students. Psychological reports. 2000; 87: 107-10. DOI: 10.2466/PRo.87.5.107-110.

19. Zhumataeva M.S., Bapaeva

M.K., Shiganova K. U. Psychological and 
psychophysiological features of students. Modern innovations. 2016; 5(7): 76-78.

20. Klimov E. A. Psychology of professional self-determination. Rostov-on-don: Phoenix Publishing house. 1996: 145-204.

21. Baurina A.B. Differences in psychological make-up of students of technical and artistic specialties. Bulletin of Moscow state regional University. Series: Psychological Sciences. 2016; 4: 114-122.

22. Gordienko, Natalia \& Silaeva, Kira. Psychological and Psychophysiological Research of the Attitude System of Students for Technical and Humanitarian Specialties. Revista Romaneasca pentru Educatie Multidimensionala. 2015; 07: 219231. DOI: 10.18662/rrem/2015.0701.16.

23. Natalya Yu. Tarabrina, Yuriy V. Kraev. Chi Kung in the structure of modern physical culture and sports activity. Pedagogiko-sihologicheskie I medico-biologicheskie problemy fizicheskoj kul'tury I sporta = Russian Journal of Physical Education and Sport. 2019; 14(4): 19-26. DOI: 10.14526/2070-4798-2019-14-4-22-31.

\section{Submitted: 23.01.2020}

\section{Author's information:}

Natalya Yu. Tarabrina - Candidate of Biologics, Associate Professor, Moscow Aviation Institute (National Research University), 125993, Russia, Moscow, A-80, GSP-3, Volokolamskoe road, House 4, e-mail: nata-tarabrina@mail.ru

Elena Yu. Grabovskaya - Candidate of Biologics, Associate Professor, Taurian Academy of Vernadsky Crimean Federal University, 2950o1, Russia, Simferopol, Studencheskaya str., House 10/12, e-mail: grabovskaya13@mail.ru

Yuriy V. Kraev - Candidate of Psychological Sciences, Moscow Aviation Institute (National Research University), 125993, Russia, Moscow, A-80, GSP-3, Volokolamskoe road, House 4, e-mail: yury.kraev@ mail.ru 